\title{
On "A new indicator for the measurement of change with ordinal scores"
}

\author{
Renan Moritz V. R. Almeida • Ronir Raggio Luiz
}

Accepted: 23 March 2013/Published online: 11 April 2013

(C) Springer Science+Business Media Dordrecht 2013

To the Editor,

In [1], we presented a new indicator of change, the $I p C$, which is based on the total improvement a group of subjects experienced over time, relatively to the total change that could be achieved by this group.

Yarlas [2], reading our paper, identified two points that he sees as limitations to our work: (a) We assumed that changes in an ordinal variable (e.g., from poor to regular, from regular to good) are linear, and (b) it is possible to identify paradoxical results if one compares groups of subjects with very different baseline scores.

We thank this opportunity to further discuss these aspects of our paper. Relatively to (a) one should note that the debate on the use of measurement scales goes is not new or unknown $[3,4]$. Precisely to avoid such problems, we stated that "In the present study, the approach is more indicated to clinician-rated scales, for which problems such as variation in the meaning of change according to the position of a subject in a scale are less important. Examples of these are physiological variables that are measured against a standardized, agreed-upon scale, developed and applied after consensus is achieved in a field" [1].

Regarding (b), we would like to point that the use of our indicator is non-problematic, for instance, when following a group of patients or when comparing groups with similar baseline scores. In fact, problems introduced by analyzing changes on groups with different baselines are very common, and the good practice of statistics demands that baseline scores be taken into account on the interpretation of such results [3].

We hope further research may provide more information not only on the validity of our proposal but also on other indicators presently used in the study of change.

\section{References}

1. Ferreira, M. L. P., Almeida, R. M. V. R., \& Luiz, R. R. (2013). A new indicator for the measurement of change with ordinal scores. Quality of Life Research, doi:10.1007/s11136-012-0288-2.

2. Yarlas, A. Commentary on "A new indicator for the measurement of change with ordinal scores". Quality of Life Research. doi: 10.1007/s11136-013-0368-y.

3. Luiz, R. R., \& Almeida, R. M. V. R. (2012). On the measurement of change in medical research. Int J Statistics in Medical Research., 1, 144-147.

4. Knapp, T. (1990). Treating ordinal scales as interval scales: An attempt to resolve the controversy. Nursing Research, 39(2), $121-123$. 